\title{
A Zero Carryover Liquid-Desiccant Air Conditioner for Solar Applications
}

Conference Paper NREL/CP-550-39798 July 2006

\section{Preprint}

A. Lowenstein

All Research, Inc.

S. Slayzak and E. Kozubal

National Renewable Energy Laboratory

To be presented at ASME International Solar Energy Conference (ISEC2006)

Denver, Colorado

July 8-13, 2006

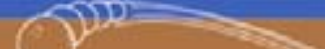




\section{NOTICE}

The submitted manuscript has been offered by an employee of the Midwest Research Institute (MRI), a contractor of the US Government under Contract No. DE-AC36-99G010337. Accordingly, the US Government and MRI retain a nonexclusive royalty-free license to publish or reproduce the published form of this contribution, or allow others to do so, for US Government purposes.

This report was prepared as an account of work sponsored by an agency of the United States government. Neither the United States government nor any agency thereof, nor any of their employees, makes any warranty, express or implied, or assumes any legal liability or responsibility for the accuracy, completeness, or usefulness of any information, apparatus, product, or process disclosed, or represents that its use would not infringe privately owned rights. Reference herein to any specific commercial product, process, or service by trade name, trademark, manufacturer, or otherwise does not necessarily constitute or imply its endorsement, recommendation, or favoring by the United States government or any agency thereof. The views and opinions of authors expressed herein do not necessarily state or reflect those of the United States government or any agency thereof.

Available electronically at http://www.osti.gov/bridge

Available for a processing fee to U.S. Department of Energy and its contractors, in paper, from:

U.S. Department of Energy

Office of Scientific and Technical Information

P.O. Box 62

Oak Ridge, TN 37831-0062

phone: 865.576 .8401

fax: 865.576 .5728

email: mailto:reports@adonis.osti.gov

Available for sale to the public, in paper, from:

U.S. Department of Commerce

National Technical Information Service

5285 Port Royal Road

Springfield, VA 22161

phone: 800.553 .6847

fax: 703.605.6900

email: orders@ntis.fedworld.gov

online ordering: http://www.ntis.gov/ordering.htm 
Proceedings of ISEC2006

ASME International Solar Energy Conference

July 8-13, 2006, Denver, CO

ISEC2006-99079

\title{
A ZERO CARRYOVER LIQUID-DESICCANT AIR CONDITIONER FOR SOLAR APPLICATIONS
}

\author{
ANDREW LOWENSTEIN \\ AIL RESEARCH, INC. \\ PRINCETON, NJ \\ ail@ailr.com \\ STEVEN SLAYZAK AND ERIC KOZUBAL \\ NATIONAL RENEWABLE ENERGY LABORATORY \\ GOLDEN, CO
}

\begin{abstract}
A novel liquid-desiccant air conditioner that dries and cools building supply air has been successfully designed, built, and tested. The new air conditioner will transform the use of directcontact liquid-desiccant systems in HVAC applications, improving comfort and indoor air quality, as well as providing energy-efficient humidity control

Liquid-desiccant conditioners and regenerators are traditionally implemented as adiabatic beds of contact media that are highly flooded with desiccant. The possibility of droplet carryover into the supply air has limited the sale of these systems in most HVAC applications. The characteristic of the new conditioner and regenerator that distinguishes them from conventional ones is their very low flows of liquid desiccant. Whereas a conventional conditioner operates typically at between 10 and $15 \mathrm{gpm}(630$ and $946 \mathrm{ml} / \mathrm{s})$ of desiccant per $1000 \mathrm{cfm}\left(0.47 \mathrm{~m}^{3} / \mathrm{s}\right)$ of process air, the new conditioner operates at $0.5 \mathrm{gpm}(32 \mathrm{ml} / \mathrm{s})$ per $1000 \mathrm{cfm}(0.47$ $\mathrm{m}^{3} / \mathrm{s}$ ). At these low flooding rates, the supply air will not entrain droplets of liquid desiccant. This brings performance and maintenance for the new liquid-desiccant technology in line with HVAC market expectations.

Low flooding rates are practical only if the liquid desiccant is continually cooled in the conditioner or continually heated in the regenerator as the mass exchange of water occurs. This simultaneous heat and mass exchange is accomplished by using the walls of a parallel-plate plastic heat exchanger as the air/desiccant contact surface. Compared to existing solid- and liquid-desiccant systems, the low-flow technology is more compact, has significantly lower pressure drops and does not "dump" heat back onto the building's central air conditioner. Tests confirm the high sensible and latent effectiveness of the conditioner, the high COP of the regenerator, and the operation of both components without carryover.
\end{abstract}

Keywords: Dehumidifier, Liquid Desiccant, Air Conditioner, HVAC, Solar Cooling

\section{INTRODUCTION}

The $20^{\text {th }}$ century was a period during which the cooling and dehumidification of homes and commercial buildings switched from being a luxury to a necessity. In the U.S. alone, air conditioning is a $\$ 10$ billion industry that uses over 4.3 quads (4.54 billion GJ) of primary energy, almost all of which comes from non-renewable sources. Perhaps equally as important as its energy use, air conditioning is often the single largest cause of overloaded electric transmission and distribution systems.

Now, at the start of the $21^{\text {st }}$ century, there is growing awareness that our approach to air conditioning must change if its benefits are to continue and even expand into the developing regions of the world. One obvious change is to design buildings so that comfortable conditions can be maintained with less active cooling and dehumidification. A second is to develop air conditioners that run on renewable energy sources.

But these changes are not enough. Other challenges now face the industry that provides systems for heating, ventilation and air conditioning (HVAC). Indoor environments are often uncomfortable and unhealthy because humidity is too high. The fundamental problem is that a cold heat exchanger, whether it is a chilled-water coil or a DX evaporator, is a poor way to dehumidify air. A 45F (7.2C) heat exchanger will typically provide $70 \%$ of its total cooling as sensible cooling (i.e., temperature reduction) and $30 \%$ as latent cooling (i.e., dehumidification). In many applications, this latent/sensible split must be reversed if indoor humidity is to be adequately controlled.

Desiccants - which are materials that have a high affinity for water vapor - can be part of a sustainable approach to maintaining healthy and comfortable indoor environments. Desiccants are unique in that they can dry air without first cooling the air below its dewpoint. Latent cooling can be more than twice sensible cooling. Once the desiccant is loaded with water, heat is used to return the desiccant to its "dry" state. The high electrical demand of the compressor in a conventional air 
conditioner is replaced by the need for thermal energy to regenerate the desiccant. This creates an important opportunity to use solar thermal energy for air conditioning.

\section{PAST WORK ON SOLAR DESICCANT COOLING}

There have been numerous attempts at capturing the benefits of desiccants in a solar air conditioner. In one of the earliest efforts, Löf proposed a solar air conditioner that used triethylene glycol (Löf, 1955). In the early 1980s, American Solar King manufactured and sold a residential solar cooling system that used a lithium-chloride solid-desiccant rotor (Coellner, 1986). When energy prices declined in the late 1980s, American Solar King converted their product to a gasfired unit. Robison conducted a 2-year field test of a solar cooling system that used a calcium-chloride liquid-desiccant conditioner (Robison, 1983). The test demonstrated the technical feasibility of this solar cooling system, but there was no attempt to commercialize the technology. Schlepp and Schultz have summarized the experiences of many solar desiccant cooling activities that followed the energy crisis of the 1970s (Schlepp and Schultz, 1984).

In addition to AIL Research, there are now at least two companies that are commercializing liquid-desiccant technology that can be used for solar cooling. L-DCS Technology is now commissioning a $350-\mathrm{kW}$ solar cooling system in Singapore (L-DCS, 2006). In 2005, Jilier Technology Development introduced the American Genius line of liquid-desiccant air conditioners at the International AirConditioning, Heating and Refrigeration Exposition (Jilier, 2005).

\section{STATE OF THE ART OF DESICCANT TECHNOLOGY}

Desiccant systems are commonly categorized as either solid or liquid types. Solid-desiccant systems most commonly use a porous rotor with face seals that create two isolated air paths through the rotor. The process air moves through one sector of the rotor, while at the same time, hot regeneration air moves through other. The rotation of the rotor permits continuous dehumidification of the process air without any valves or dampers periodically redirecting the air flows. Because there is no active cooling within the rotor and the rotor itself transfers some heat from the regeneration air to the process air, the dry process air leaves the rotor at a higher enthalpy than it entered.

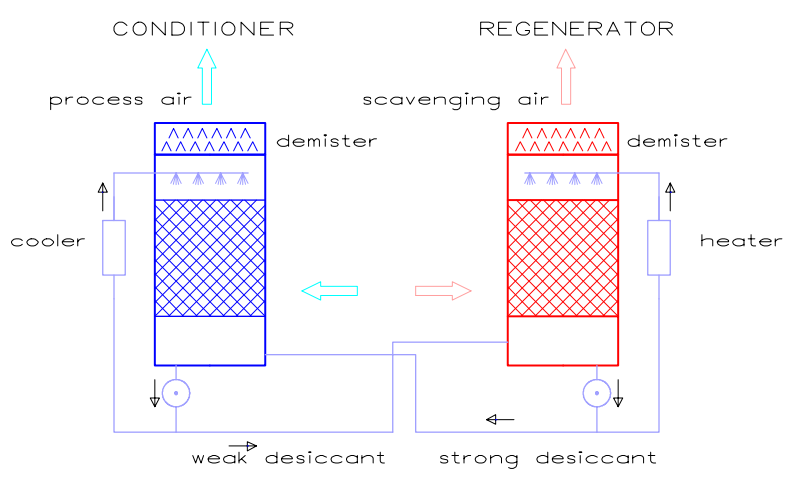

Figure 1 - Operation of conventional liquid-desiccant system
In most HVAC applications, the process air leaving the desiccant rotor must be cooled before it is supplied to the building.

Figure 1 shows the configuration of most liquiddesiccant systems now being sold for industrial applications. Both the conditioner and regenerator are porous, adiabatic beds that are flooded with desiccant. The desiccant is first cooled before it is sprayed onto the bed of the conditioner. The process air flows through this bed and is both cooled and dried by the desiccant.

A slip stream of desiccant (typically an order of magnitude smaller than the flooding rate) is continually recirculated between the conditioner and a regenerator where the desiccant is re-concentrated using thermal energy. Again, the desiccant flows over a porous bed of contact media. However, the desiccant is now first heated, typically to between $180 \mathrm{~F}$ and $210 \mathrm{~F}$ ( $82 \mathrm{C}$ and $99 \mathrm{C}$ ), before it is sprayed onto the bed. Air flows through the bed, scavenges the water vapor that is desorbed from the desiccant, and rejects it to ambient.

The flooding rate in both the conditioner and regenerator of a conventional liquid desiccant system is relatively high for two reasons: (1) the entire internal area of the contact bed must be well wetted, and (2) the desiccant flow must have sufficient thermal capacity to ensure that the temperature of the desiccant does not increase or decrease significantly as water is absorbed or desorbed. At the high flooding rates, small droplets of desiccant will be created as the desiccant cascades down through the bed. These small droplets are entrained by the air flowing through the bed. Consequently, a conventional liquid-desiccant system must use a droplet filter or demister to prevent carryover of desiccant out of the conditioner and regenerator. In well-maintained systems, the droplet filter/demister will essentially eliminate desiccant carryover.

\section{A LOW-FLOW ZERO-CARRYOVER LIQUID DESICCANT CONDITIONER AND REGENERATOR}

The present need for increased ventilation and better humidity control within residential and commercial buildings has spurred interest in desiccant systems. However, most sales have been solid-desiccant systems. While the sales of both systems are limited by their higher costs, liquid-desiccant systems are perceived as having more intensive maintenance requirements, which further depress sales. ${ }^{1}$

A new generation of liquid-desiccant conditioners and regenerators that meets the needs of HVAC applications has been developed and proven. The two most important improvements are (1) desiccant flooding rates have been decreased by a factor of 10 to 20 , and (2) contact surfaces are no longer adiabatic, being continually cooled in the conditioner and continually heated in the regenerator. These two changes are related in that when the desiccant flooding rate is decreased, the thermal capacitance of the flow is proportionately

\footnotetext{
${ }^{1}$ A dedicated outdoor air system based on vapor-compression technology will cost on the order of $\$ 6$ per $\mathrm{cfm}(\$ 12.70$ per 1/s), while one based on liquid or solid desiccants will cost closer to $\$ 10$ per cfm $(\$ 21.20$ per $1 / \mathrm{s})$.
} 
decreased. If the contact surface was adiabatic, the desiccant's temperature would either rapidly increase in the conditioner or rapidly decrease in the regenerator, and the driving potential for the exchange of water vapor would be lost.

The preceding two improvements in liquid-desiccant technology lead to a much more competitive cooling system. Compared to the technology now in use, a low-flow liquiddesiccant air conditioner (LDAC) will

- have much lower pressure drops

- be more compact

- $\quad$ produce a greater cooling effect (e.g., lower cfm/ton)

- more deeply dry the process air, and

- have a higher COP.

Perhaps most importantly, both the low-flow conditioner and regenerator will operate without the entrainment of desiccant droplets by the air streams (i.e., zero desiccant carryover).

As shown in Figure 2, a LDAC that uses the low-flow technology has three main components: (1) the conditioner, (2) the regenerator, and (3) the interchange heat exchanger. The conditioner is a parallel-plate heat exchanger in which the plates are water-cooled. Films of desiccant flow in thin wicks on the outer surfaces of the plates. The process air (horizontal arrows) flows through the gaps between the plates and comes in contact with the desiccant. The desiccant absorbs water vapor from the air, and the heat that is released is transferred to the cooling water. The air leaves the conditioner drier and at a lower enthalpy (i.e., cooling occurs, although most of the cooling may be latent rather than sensible).

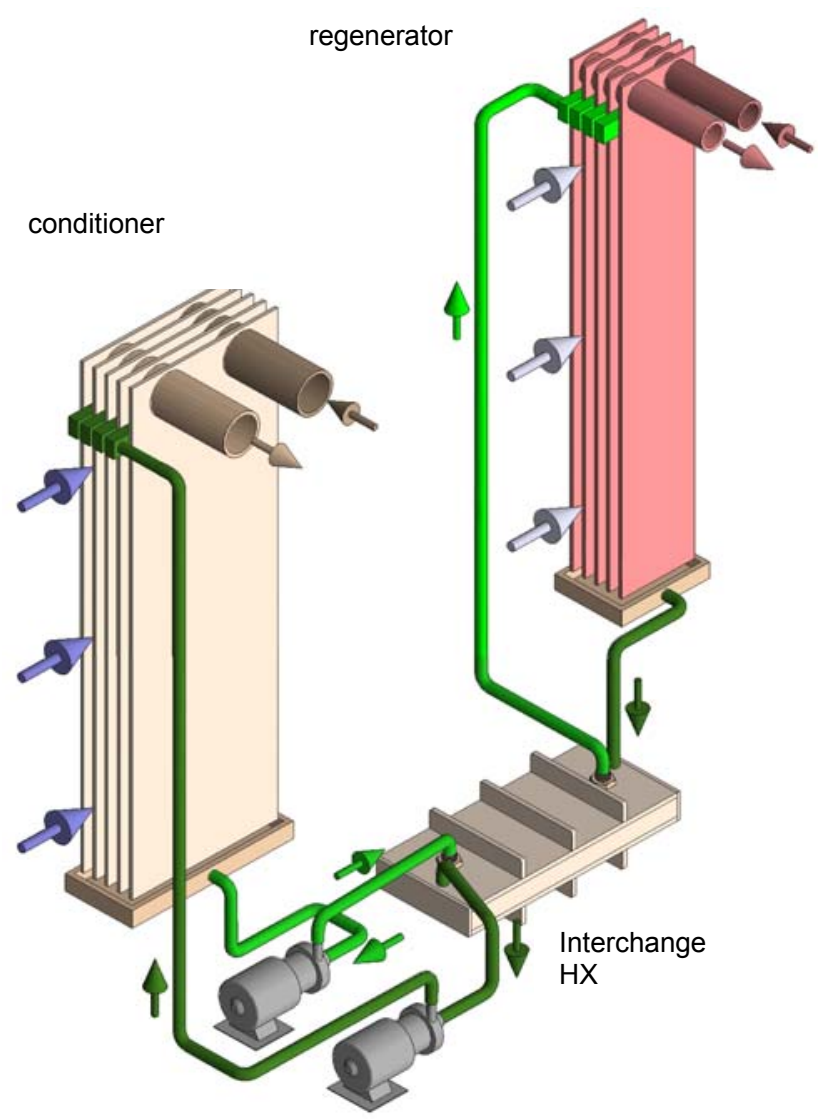

Figure 2 - Operation of a low-flow liquid-desiccant air conditioner
The water absorbed by the desiccant in the conditioner is desorbed in the regenerator. This component is again a parallel-plate heat exchanger, but now hot water (or other heattransfer fluid) flows within the plates. The hot desiccant films that flow on the outer surfaces of the plates desorb water to a flow of scavenging air (horizontal arrows) that rejects the water to ambient.

The interchange heat exchanger, which transfers heat from the hot, strong desiccant leaving the regenerator to the cool, weak desiccant flowing to the regenerator, performs a dual function. It improves the efficiency of the regenerator by preheating the weak desiccant. It also increases the cooling provided by the conditioner by reducing the heat load imposed by the strong desiccant.

\section{THE IMPLEMENTATION OF LOW-FLOW TECHNOLOGY}

Although many liquids have desiccant properties, solutions of halide salts, particularly lithium chloride and calcium chloride, are the most viable liquid desiccants for solar applications. However, the high chloride concentrations in solutions of these salts eliminate even most stainless steels from service in contact with the desiccant. If maintenance is to be acceptable, all wetted surfaces of a LDAC should be a plastic with suitable properties.

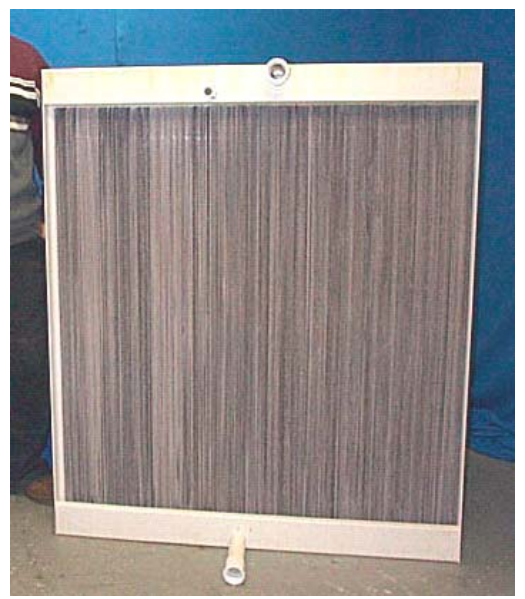

\section{Figure 3 - A 6,000 cfm low-flow liquid-desiccant conditioner}

Figure 3 shows a plastic-plate heat exchanger that functions as a 6,000-cfm liquid-desiccant conditioner. The plates are made from a plastic extrusion. The cross-section of each plate, which is shown in Figure 4, is $0.1 \mathrm{in}$. by $12.0 \mathrm{in}$. (2.5 $\mathrm{mm}$ by $305 \mathrm{~mm}$ ), with 110 cooling passages running the

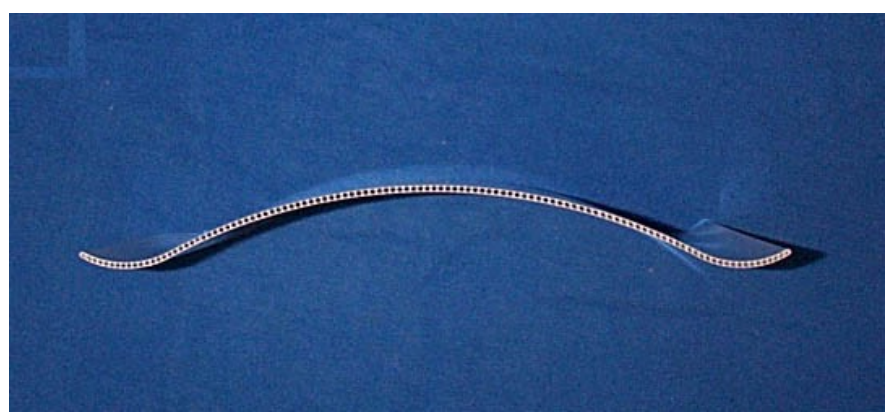

Figure 4 - Cross-section of plate extrusion 
length of the extrusion. The plates have a thin - approximately $0.020 \mathrm{mil}(0.5 \mathrm{~mm})$ - wick covering their surfaces to ensure even wetting by the desiccant. Each plate is bonded to an upper and lower end-piece. For the conditioner shown in Figure 3, 198 plate/end-piece assemblies are stacked and bonded together. When stacked and bonded, the upper endpieces form two isolated flow circuits: one for distributing desiccant onto the plate surfaces, and the other for circulating a cooling fluid within the plates. In a similar fashion, the lower end-pieces form a collection sump for the desiccant that flows off the plates. Additional features of the conditioner are described in U.S. Patent $6,745,826$ and several pending foreign patents.

The preceding conditioner can operate effectively at desiccant-to-air mass flow ratios 20 to 30 times less than those in a conventional liquid-desiccant conditioner. At these low desiccant flows, the liquid films on the plates of the conditioner are contained within the wicks that cover the plates. As described in a later section, this design for the conditioner has a large operating envelope within which the process air does not entrain droplets of desiccant. Furthermore, because droplets are not created when the desiccant is either delivered to or collected from the plates, droplet carryover is completely suppressed during normal operation.

A low-flow regenerator functions similarly to a conditioner, the major difference being that now a hot fluid flows within the plates instead of a coolant. The high operating temperatures forces several design changes.

As with the conditioner, polymers can best deal with the corrosiveness of the liquid desiccant. Because both the efficiency and water-removal capacity of a scavenging-air regenerator increase with operating temperature, a polymer should be selected that withstands high temperatures (e.g., temperatures on the order of $212 \mathrm{~F}[100 \mathrm{C}]$ ). Polymers in the polysulfone family can meet this temperature requirement.

Thermal expansion is more of an issue in designing the regenerator. Polymers have coefficients of thermal expansion (CTE) that are an order of magnitude greater than

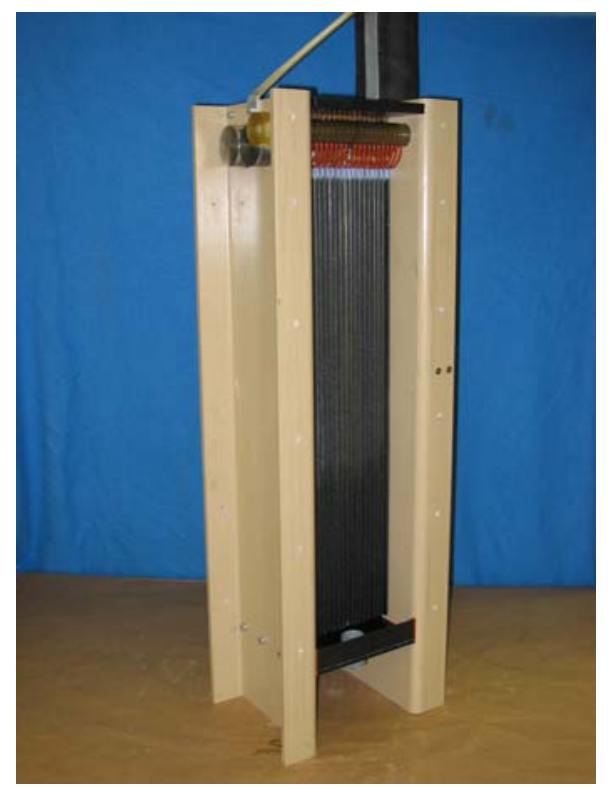

Figure 5 - A low-flow scavengingair regenerator

previously described for the conditioner would make a poor regenerator because it fixes both ends of the plates to common manifolds. A non-uniformity in temperature between neighboring plates will induce stresses that could break the adhesive seals within the structure. The design for the regenerator locates the inlet and outlet manifolds for the hot heat transfer fluid at the same end of the plates. The passages within the plates create a two-pass flow circuit between the inlet and outlet manifolds. With both fluid connections at the same end, the opposite ends of the plates are unconstrained. Each plate can expand independently of its neighbor.

Figure 5 shows a low-flow scavenging-air regenerator with "hanging" plates. Each plate is 0.12 in. thick, 4.5 in. wide and 24 in. long. ( $3 \mathrm{~mm} \times 11.4 \mathrm{~cm} \times 61 \mathrm{~cm})$ The 21 plates of the regenerator provide a design water-removal capacity of $18 \mathrm{lb} / \mathrm{h}$ $(8.2 \mathrm{~kg} / \mathrm{h})$.

\section{A COMPARISON OF THE LOW-FLOW CONDITIONER WITH CONVENTIONAL DESICCANT TECHNOLOGY}

A unique feature of the low-flow liquid-desiccant conditioner is the integration of heat and mass transfer in one low pressuredrop component. In contrast to this dual-function configuration, the rotor of a solid-desiccant system does only adiabatic drying with the process air being cooled in a separate heat exchanger. For a conventional liquid-desiccant conditioner, the process air is both dried and cooled, but a separate heat exchanger must be used to cool the desiccant before it flows onto the contact bed.

By combining heat and mass transfer into a single component, the low-flow liquid-desiccant conditioner will be more compact and have lower air-side pressure drops than existing desiccant technologies. The lower desiccant flow rate compared to a conventional liquid-desiccant conditioner also reduces pump power by close to an order of magnitude.

The performance of a low-flow liquid-desiccant conditioner is next compared with that of conventional liquiddesiccant and solid-desiccant systems. Manufacturer's data is used to predict the performance of the two conventional systems constraints:

All three systems are designed to meet the following

- $6,000 \mathrm{scfm}\left(2.8 \mathrm{~m}^{3} / \mathrm{s}\right)$ of outdoor air at $95 \mathrm{~F}$ and $118 \mathrm{gr} / \mathrm{lb}(35 \mathrm{C}$ and $16.9 \mathrm{~g} / \mathrm{kg})$ are processed

- Cooling tower water supplied at $86 \mathrm{~F}(30 \mathrm{C})$ is used for cooling

- Air velocities at the face of the rotor or conditioner are $400 \mathrm{fpm}(2 \mathrm{~m} / \mathrm{s})$.

With the preceding constraints, the low-flow liquiddesiccant conditioner that has been described in the preceding section and which operates with $44 \%$ lithium chloride solution will supply air at $93.3 \mathrm{~F}, 24.4 \% \mathrm{rh}$, and $57.0 \mathrm{gr} / \mathrm{lb}(34.1 \mathrm{C}$ and $8.14 \mathrm{~g} / \mathrm{kg}$ ). The air-side pressure drop will be about $0.3 \mathrm{in}$. w.c. $(75 \mathrm{~Pa})$, and the water-side pressure drop will be less than $1 \mathrm{psi}$ $(6,900 \mathrm{~Pa})$. If two conditioners are placed in series, air will be supplied at $92.6 \mathrm{~F}, 18.3 \% \mathrm{rh}$, and $41.7 \mathrm{gr} / \mathrm{lb}(33.7 \mathrm{C}$ and 5.95 $\mathrm{g} / \mathrm{kg}$ ), and the air-side pressure drop will be doubled. The desiccant circulator pump will have a $1 / 5^{\text {th }} \mathrm{HP}$ motor that will draw $200 \mathrm{~W}$ (one pump/motor per conditioner).

For the conventional, high-flooding-rate conditioner, the cooling-tower water cools the liquid desiccant before it is sprayed onto the contact bed. Assuming a conditioner configuration in which the process air flows horizontally 
through the bed, a representative supply air condition will be $97 \mathrm{~F}, 20.3 \% \mathrm{rh}$, and $53.0 \mathrm{gr} / \mathrm{lb}(36 \mathrm{C}$ and $7.57 \mathrm{~g} / \mathrm{kg})$. The airside pressure drop through the conditioner will be 1.3 in. w.c. (324 Pa). The desiccant recirculator pump will have a $2 \mathrm{HP}$ motor that will draw $1.5 \mathrm{~kW}$.

The conventional conditioner will also be larger than the low-flow conditioner. Not including inlet and outlet plenums, a conventional conditioner that processes a nominal $7,500 \mathrm{cfm}$ will be 61 in. x 60 in. x 92 in. (W x D x H; $1.55 \mathrm{~m} \mathrm{x}$ $1.52 \mathrm{~m} \times 2.34 \mathrm{~m})$. For the same air flow, the low-flow conditioner will be 65 in. $x 40$ in. $x 77$ in. (1.65 m x $1.02 \mathrm{~m} \mathrm{x}$ $1.96 \mathrm{~m})$.

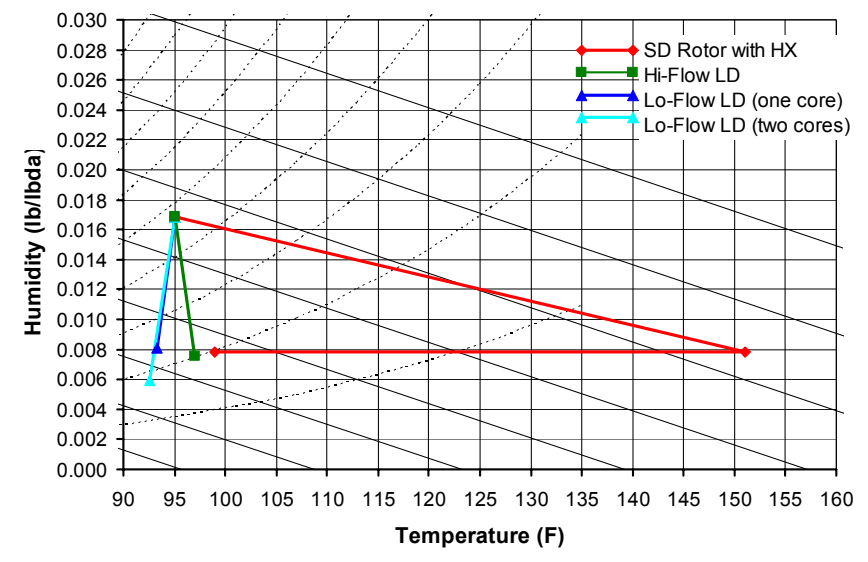

Figure 6 - Comparative performance of solid- and liquid-desiccant systems

For the solid desiccant system, the rotor is $400 \mathrm{~mm}$ deep and regenerated at $250 \mathrm{~F}(121 \mathrm{C})$. The hot, dry process air leaving the rotor is cooled in a 4-row finned tube heat exchanger that has an $80 \%$ effectiveness and is cooled with cooling tower water. At these operating conditions, the process air leaves the rotor at $151 \mathrm{~F}$ and $55.0 \mathrm{gr} / \mathrm{lb}(66.1 \mathrm{C}$ and $7.85 \mathrm{~g} / \mathrm{kg}$ ). The heat exchanger downstream of the rotor cools the supply air to $99 \mathrm{~F}$ and $19.8 \% \mathrm{rh}(37.2 \mathrm{C})$ with no change in humidity. The pressure drop through the rotor is about $1.5 \mathrm{in}$. w.c. (373 Pa) and through the heat exchanger, 0.24 in. w.c. (60 $\mathrm{Pa})$. The drive motor for the rotor draws on the order of $200 \mathrm{~W}$ (at $6,000 \mathrm{cfm}\left[2.83 \mathrm{~m}^{3} / \mathrm{s}\right.$ ], each 1.0 in. w.c. [250 Pa] air-side pressure drop increases fan power by about $1.3 \mathrm{~kW}$ ).

The psychrometric performances of the preceding four systems are compared in Figure 6, in which the $\mathrm{x}$-axis is absolute humidity expressed in mass of water per mass of dry air. The single low-flow liquid-desiccant conditioner, the soliddesiccant rotor, and the conventional liquid-desiccant conditioner all supply air at about the same humidity. The single low-flow liquid-desiccant conditioner does deliver air at a lower temperature and slightly lower enthalpy. A more important difference is that the low-flow liquid desiccant conditioner delivers this cooling with only a 0.3 in. w.c. (75 Pa) pressure drop, while the other two systems have pressure drops between 1.3 and 1.7 in. w.c. ( 324 and $423 \mathrm{~Pa}$ ). The use of two low-flow conditioners in series increases latent cooling by $25 \%$ and total cooling by $14 \%$, but still has a pressure drop that is less than one-half that of the alternative systems.

\section{A COMPARISON OF THE LOW-FLOW REGENERA- TOR WITH CONVENTIONAL DESICCANT TECHNOLOGY}

Both the solid-desiccant and liquid-desiccant systems can use solar thermal energy for regeneration. This thermal energy can be provided by either glazed, flat-plate collectors or evacuatedtube collectors. (A third type of collector-concentrating, tracking collectors - tend to be used in very large systems and are not compared here.) Flat-plate collectors are less expensive, but they supply thermal energy at a lower temperature: their installed cost will be on the order of $\$ 25$ to $\$ 40$ per square foot (\$269 to $\$ 431$ per square meter), and at peak summer conditions, they will deliver between $50 \%$ and $60 \%$ of the incident solar radiation as hot water at $180 \mathrm{~F}(82 \mathrm{C})$. Evacuated-tube collectors will have an installed cost that is 1.5 to two times that of a flat-plate collector, but they will achieve the same $50 \%$ to $60 \%$ collection efficiency when operating at $250 \mathrm{~F}$ (121C) or higher.

The selection of the collectors for a solar cooling system is a trade-off between their cost and performance. In general, the Coefficient of Performance (COP) for desiccant regeneration-defined as the thermal energy needed to evaporate a unit mass of pure water divided by the thermal energy supplied to the regenerator to remove the same mass of water from the desiccant-increases at higher temperatures. For liquid-desiccant systems, the improvement in COP with increasing regeneration temperature is most dramatic when the desiccant is regenerated in two stages (similar to the doubleeffect generator of an absorption chiller). While gas-fired twostage desiccant regenerators have been developed, no comparable technology is available for solar applications. When used with a single-stage liquid-desiccant regenerator, such as the scavenging-air regenerator shown in Figure 5, the higher operating temperature of the evacuated-tube collector will not justify its higher cost.

As discussed in a later section, the $44 \%$ lithiumchloride solution that produces the performance shown in Figure 6 for the low-flow liquid-desiccant systems can be regenerated at a thermal COP of 0.80 in a low-flow regenerator that operates at $180 \mathrm{~F}(82 \mathrm{C})$. On a peak summer day, a glazed, flat-plate collector can deliver between $50 \%$ and $60 \%$ of the incident solar energy to the regenerator at this temperature. Thus, based on incident solar energy, the regeneration COP for the liquid desiccant will be between 0.40 and 0.48 . Assuming a collector installed cost of $\$ 32.50$ per square foot $(\$ 350$ per square meter) and a peak solar insolation of $317 \mathrm{Btu} / \mathrm{hr}^{-\mathrm{ft}^{2}}$ $\left(1,000 \mathrm{~W} / \mathrm{m}^{2}\right)$, the solar collectors cost $\$ 2,800$ per peak ton (\$796 per peak kW) of latent cooling.

A conventional packed-bed regenerator that operates at the same conditions as the preceding low-flow regenerator will have a thermal COP of 0.55 . The flat-plate solar collectors that provide thermal energy to this regenerator will cost $\$ 4,070$ per peak ton $(\$ 1,158$ per peak $\mathrm{kW})$ of latent cooling.

The performance for the solid-desiccant cooling system shown in Figure 6 assumes that the desiccant is regenerated at $250 \mathrm{~F}$. This relatively high temperature can be supplied by evacuated-tube collectors, but not the lower cost flat-plate collectors. At this temperature, the solid-desiccant regeneration $\mathrm{COP}$ will be 0.5 , and the efficiency of the solar 
collectors on a peak summer day will be between $50 \%$ and $60 \%$ (i.e., percent of incident solar radiation delivered to the heater for the desiccant regenerator). Thus, based on incident solar energy, the regeneration COP for the solid desiccant will be between 0.25 and 0.30 . Assuming a collector installed cost of $\$ 65.00$ per square foot ( $\$ 700$ per square meter) and a peak solar insolation of $317 \mathrm{Btu} / \mathrm{hr}^{-\mathrm{ft}^{2}}\left(1,000 \mathrm{~W} / \mathrm{m}^{2}\right)$, the solar collectors cost $\$ 9,000$ per peak ton $(\$ 2,560$ per peak $\mathrm{kW})$ of latent cooling.

\section{ENERGY STORAGE WITH LIQUID DESICCANTS}

A competitive solar cooling system must store energy if it is to effectively use the thermal energy provided by its solar collectors. Peak solar insolation will occur mid-day, while cooling loads for the building peak in the afternoon and extend into the early evening. At a minimum, several hours of storage are needed to accommodate this mismatch.

A liquid-desiccant cooling system has an important advantage over all alternatives in solar applications because of the ease with which concentrated desiccant can be stored (Kessling et al., 1998). All PV-based cooling systems will be penalized for the expense and inefficiency of battery storage. Although these systems can store "cooling" as either chilled water or ice, both options impose additional economic penalties. Chilled-water storage requires very large, insulated storage tanks. Ice storage systems can be much smaller, but they are inefficient. (In conventional applications, ice can be made at night when electric rates are low, and the lower ambient temperatures compensate for the low evaporator temperatures needed to make ice. For a PV-based cooling system, ice storage would require making ice during the higher ambient temperatures of mid-day.)

Solar thermal cooling systems that use absorption chillers, adsorption chillers, or solid-desiccant systems must store energy as hot water which can later be used to run the cooling system. For single-effect technologies, hot water must be stored at between $190 \mathrm{~F}$ and $210 \mathrm{~F}$ ( $88 \mathrm{C}$ and $99 \mathrm{C}$ ). Because the COP for single-effect technologies will be on the order of 0.6 , approximately $60 \%$ more thermal energy must be stored than the cooling that is eventually provided. The higher COP of double-effect technologies (COPs closer to 1.0), greatly reduces the quantity of thermal energy that must be stored, but now the storage temperature must be over $320 \mathrm{~F}(160 \mathrm{C})$.

Compared to batteries, hot water, ice, and chilled water, the storage of concentrated desiccant imposes a relatively modest economic penalty and no efficiency penalty on the liquid-desiccant cooling system. Concentrated desiccant can be stored in uninsulated plastic tanks with no loss in cooling potential over time. For cooling systems that use a solution of lithium chloride that cycles between $38 \%$ and $44 \%$, the density of storage will be 8.3 gallons per ton-hour latent cooling (2.48 liter/MJ). This is a lower volumetric requirement than the 10 gallons per ton hour (2.99 liter/MJ) that is typical of ice storage. At $\$ 2.50$ per pound $(\$ 5.50$ per $\mathrm{kg}$ ) for anhydrous lithium chloride, the cost for storage will be about $\$ 80$ per tonhour (\$6.32 per MJ), a value that is comparable to ice storage.

A solar cooling system that uses liquid desiccants can dramatically reduce its cost for storage by replacing lithium chloride with calcium chloride. The change does reduce the cooling capacity for the system because calcium chloride is a significantly weaker desiccant than lithium chloride. At typical high-load conditions, the switch to a $44 \%$ calcium chloride solution will decrease the total cooling effect by between $25 \%$ and $30 \%$. While this loss is significant, the switch will reduce storage costs to less than $\$ 15$ per ton-hour $(\$ 1.19$ per MJ). More storage can then be part of the solar cooling system, which will greatly improve the utilization of the solar collectors.

\section{PERFORMANCE TESTING OF THE LOW-FLOW CONDITIONER}

The pre-production prototype described in this section is the product of a 5-year development effort that has progressively improved the cooling performance, pressure drop, and carryover suppression of low-flow liquid-desiccant conditioners. The $1,200-\mathrm{cfm}\left(0.566-\mathrm{m}^{3} / \mathrm{s}\right)$ prototype had 42 plates, each plate 4 feet in length, and a $3.47-\mathrm{ft}^{2}\left(0.323-\mathrm{m}^{2}\right)$ face area.

Testing was conducted at the Advanced Thermal Conversion Lab of the National Renewable Energy Laboratory's (NREL) Center for Buildings and Thermal Systems. This research facility accelerates development of high efficiency HVAC concepts by rapidly and accurately evaluating the thermodynamic performance and design features of full-scale prototypes and comparing them to the state-of-theart. The lab's current technical specifications and unique capabilities are detailed in Slayzak and Ryan (2004). Airflows in these experiments were measured to $\pm 2 \%$; drybulb and dewpoint temperatures to $\pm 0.3^{\circ} \mathrm{F}\left( \pm 0.2^{\circ} \mathrm{C}\right)$. Uncertainties for the resulting grain depressions are therefore approximately $\pm 2 \mathrm{gr} / \mathrm{lb}(0.3 \mathrm{~g} / \mathrm{kg})$ for dry inlet air and $\pm 3 \mathrm{gr} / \mathrm{lb}(0.4 \mathrm{~g} / \mathrm{kg})$ at the most humid conditions examined. Desiccant concentrations were monitored manually throughout testing by a temperaturecompensated hydrometer with $0.1 \%$ concentration graduations and were controlled to within \pm 0.25 concentration points of reported values.

The performance of a low-flow prototype and a conventional packed-bed conditioner were measured at this facility. The prototype was tested under the following conditions:

- Desiccant - commercial lithium chloride and water solution

- Inlet air to conditioner drybulb temperature - 86F (30C).

- Cooling water inlet temperature and desiccant inlet temperature - set to provide an outlet drybulb temperature from the conditioner equal to the inlet drybulb temperature

- Cooling water flowrate - $15 \mathrm{gpm}(56.8 \mathrm{l} / \mathrm{min})$

- Desiccant flowrate $-0.5 \mathrm{gpm}(1.9 \mathrm{l} / \mathrm{min})$.

An important objective in developing the low-flow liquid-desiccant technology was to reduce the air-side pressure drop through the conditioner. The data in Figure 7 show that at the design face velocity of $400 \mathrm{fpm}(2.0 \mathrm{~m} / \mathrm{s})$, the pressure drop for the prototype is approximately one-tenth that for the conventional conditioner: 0.3 in. w.c. versus 3.4 in. w.c. (75 Pa versus $846 \mathrm{~Pa}$ ).

Desiccant concentration has a negligible effect on pressure drop at the design face velocity. At twice the design 
flow rate of desiccant, an increase in desiccant concentration from $36 \%$ to $44 \%$ produced a $15 \%$ increase in air-side pressure.

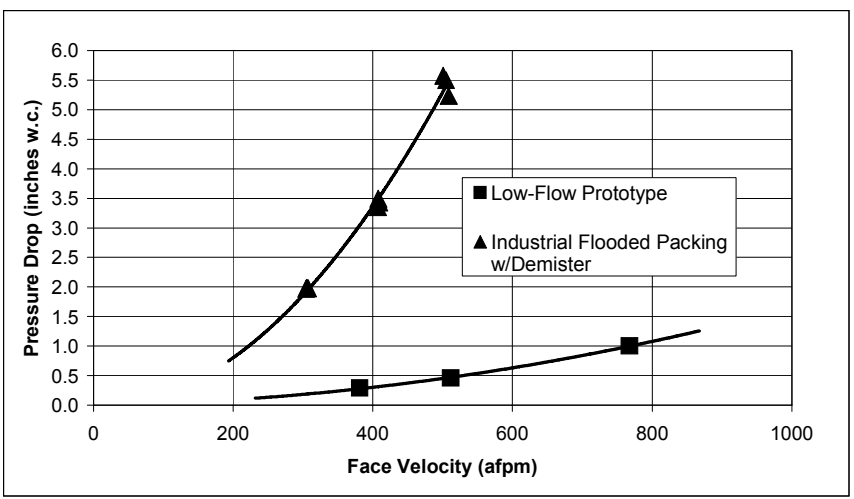

Figure 7. Comparison of the pressure-drop characteristics of a low-flow conditioner and a conventional conditioner

Figure 8 compares the dehumidification provided by the low-flow prototype with that of a conventional packed-bed conditioner. (The 100 and 150 grain/pound full scales of the $\mathrm{x}$ axis and y-axis in Figure 8 correspond to 14.3 and $21.4 \mathrm{~g} / \mathrm{kg}$.) Both units operated at a face velocity of $400 \mathrm{sfpm}(2.0 \mathrm{~m} / \mathrm{s})$. The temperatures of the cooling water to the low-flow prototype and the desiccant to the industrial unit were adjusted so that at each operating point, the supply air temperature was 86F (30C).

As shown in Figure 8, when processing air at $115 \mathrm{gr} / \mathrm{lb}$ and $86 \mathrm{~F}(16.4 \mathrm{~g} / \mathrm{kg}$ and $30 \mathrm{C})$, the low-flow prototype provided $57 \mathrm{gr} / \mathrm{lb}(8.1 \mathrm{~g} / \mathrm{kg})$ of dehumidification when the inlet desiccant concentration was $44 \%$. The packed-bed unit provided almost the same dehumidification when the inlet desiccant concentration was $39 \%$.

The packed-bed conditioner matched the dehumidification of the low-flow prototype when supplied with weaker desiccant. Although this may appear to be an advantage for the packed-bed conditioner, the advantage disappears when considering the concentration that must be returned from the regenerator. The low-flow prototype operates in a "once through" mode: the conditioner is supplied with concentrated desiccant from the regenerator, and the entire

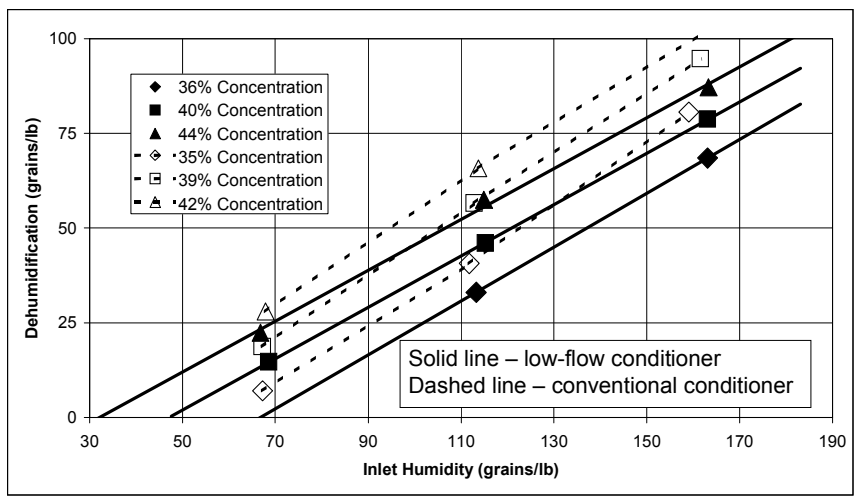

Figure 8 - A comparison of the dehumidification provided by the low-flow conditioner and a conventional conditioner as a function of inlet humidity and desiccant concentration flow of the weak desiccant leaving the conditioner is sent to the regenerator. The packed-bed conditioner operates with high recirculation. The concentration of the desiccant that floods the packed bed is close to that of the weak desiccant that drains off it. In the preceding comparison, there is a 5.5-point change in desiccant concentration across the low-flow conditioner. The regenerator, therefore, must supply $44.5 \%$ desiccant to the packed-bed conditioner if it is to match the performance of the low-flow conditioner operating with $44 \%$ desiccant.

At the $115 \mathrm{gr} / \mathrm{lb}(16.4 \mathrm{~g} / \mathrm{kg})$ operating point, the lowflow conditioner was supplied with cooling water at $79 \mathrm{~F}$ (26.1C), and the industrial unit was supplied with desiccant at $81 \mathrm{~F}(27.2 \mathrm{C})$. Assuming that the desiccant is cooled in a $67 \%$ effective heat exchanger, then this heat exchanger must be supplied with cooling water at 75F (23.9C).

The laboratory tests illustrate the advantages offered by the low-flow desiccant technology. For two conditioners that provide identical cooling, the low-flow conditioner operates with weaker desiccant, higher temperature cooling water, and, most importantly, an air-side pressure drop that is about one-tenth that of the conventional flooded-bed conditioner and its mist eliminators.

Additional performance data for the low-flow liquiddesiccant conditioner from tests at the Advanced Thermal Conversion Laboratory appear in the report by Lowenstein et al. (2005).

\section{VERIFICATION OF THE ZERO-CARRYOVER OPERATION OF THE LOW-FLOW CONDITIONER}

Tests at the Advanced Thermal Conversion Lab verified that at design operating conditions droplets of desiccant are not entrained by the air flowing through the low-flow liquiddesiccant conditioner. Two approaches were used to map the operating envelope for the prototype: visual inspection for desiccant bridging between the plates and laser particle counting/sizing.

Particle counting was accomplished using a single LasairII Model 310 laser particle counter capable of counting total airborne particle concentrations and grouping them in bins by aerodynamic diameter. The bins for this unit were 0.5 0.7 microns, $0.7-1$ microns, 1-2 microns, 2-5 microns, 5-10 microns, and $>10$ microns.

Outdoor air supplied to the prototype during testing was filtered through a $90 \%$ effective pleated box filter to establish a particle challenge that was well below the sensor's saturation limit of $>375,000$ particles $/ \mathrm{ft}^{3}\left(1.3 \times 10^{7}\right.$ particles $/ \mathrm{m}^{3}$ ). Two isokinetic sampling probes were positioned upstream and downstream from the prototype. They were attached via 6-foot (1.8-m) sampling tubes to the sensor so that inlet and outlet concentrations could be alternately measured. The sampling tubes were designed so that they did not trap particles. The pressure differential between the duct from which sample air was drawn and the room to which the sensor discharged sample air was managed to allow the sensor's internal sampling fan to maintain its continuous sample flow of $1 \mathrm{cfm}(0.47 \mathrm{l} / \mathrm{s})$. Each sample point was averaged over approximately 30 seconds. The sensor does not distinguish between solid particles expected in ambient air at the inlet and any liquid droplets entrained into the outlet airflow. The sensor 
rarely indicated any particles greater than 10 microns; this is reasonable considering the filtration implemented, the air supply duct flow conditions, and the settling time for such large airborne particulates.

Figure 9 shows the particle counts for steady-state operation at $400 \mathrm{sfpm}(2.0 \mathrm{~m} / \mathrm{s})$ and $0.5 \mathrm{gpm}(1.89 \mathrm{l} / \mathrm{min})$ desiccant flow. (In Figure 9, the 5,000 $\mathrm{per}^{3} \mathrm{ft}^{3}$ that is the full scale of the $\mathrm{x}$-axis equals $176,600 \mathrm{per}^{3}$.) The outlet particle count closely tracks the inlet challenge. (Similar tests of a flooded packed bed showed that the air downstream of the mist eliminators contained tens to hundreds of thousands of droplets per cubic foot of air in the 0.5-0.7 micron size range.) Because negligible particle arrestance is expected within the prototype as a result of laminar airflow between the parallel plates, droplet generation is inferred to be zero. Because of the need to switch sampling tubes, purge them, reach steady state in the sensor, and then average a sample reading, the time between points in the figure varied from 2 to 3 minutes.

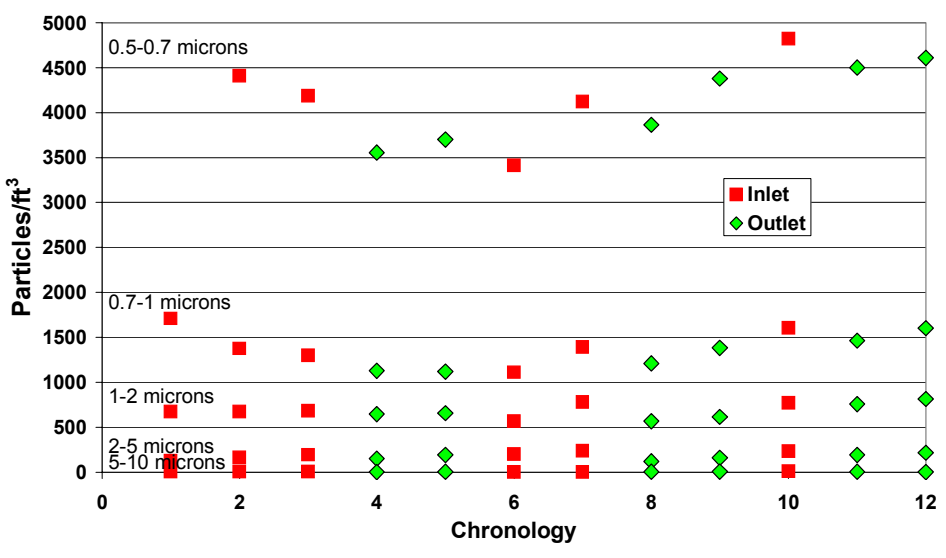

Figure 9 - Particle concentrations at inlet and outlet of lowflow liquid-desiccant conditioner

The primary mechanism for droplet generation in the parallel-plate prototype is bridging of desiccant between the plates and subsequent shattering of the liquid bridge by the airflow. Other mechanisms include air bubbles in the desiccant feed line that sputter as they exit the distribution header onto the wicks and high air and/or desiccant flow rates that lead to thick desiccant films at the trailing edges of the plates that bridge the air gaps. These mechanisms, which can be visually detected, were not present during the particle counting tests.

Figure 10 summarizes a rough operating envelope for zero desiccant carryover as determined by visual inspection. (In Figure 10, the 1.25-gpm and 800-fpm full scales of the $\mathrm{x}$ axis and y-axis equal $4.72 \mathrm{l} / \mathrm{min}$ and $4.07 \mathrm{~m} / \mathrm{s}$.) Desiccant flow, desiccant concentration, and airflow were varied to see under what combinations the system was able to suppress carryover. At $44 \%$ concentration, the highest tested, and 400 afpm (2.0 $\mathrm{m} / \mathrm{s}$ ) face velocity droplet generation was not observed below $0.75 \mathrm{gpm}(2.84 \mathrm{l} / \mathrm{min})$. At $500 \mathrm{afpm}(2.5 \mathrm{~m} / \mathrm{s})$, the operating envelope became more restricted with carryover suppressed at desiccant flows below $0.5 \mathrm{gpm}(1.89 \mathrm{l} / \mathrm{min})$. Pushing the conditioner to $750 \mathrm{afpm}(3.8 \mathrm{~m} / \mathrm{s})$ required a further reduction to $0.25 \mathrm{gpm}(0.95 \mathrm{l} / \mathrm{min})$. The operating envelope for desiccant flow could be extended by $0.25 \mathrm{gpm}(0.95 \mathrm{l} / \mathrm{min})$ at all air flow when the concentration was reduced to $40 \%$. A further $0.25 \mathrm{gpm}(0.95 \mathrm{l} / \mathrm{min})$ increase was possible at $36 \%$ concentration. A 1.0 -gpm $(3.78 \mathrm{l} / \mathrm{min})$ desiccant flow appeared to be the prototype's limit under all operating conditions because at this rate, the desiccant flow was no longer completely contained within the wicks that cover the plate surfaces. Once the desiccant film is thicker than the wick, the fluid dynamic shear of even a low airflow can move desiccant to the plate trailing edges, causing bridging and carryover.

These tests demonstrate an operating envelope for the low-flow conditioner that allow it to meet equipment size and performance requirements (e.g., nominal operation at $400 \mathrm{fpm}$ $[2.0 \mathrm{~m} / \mathrm{s}]$ and $0.6 \mathrm{gpm}[2.28 \mathrm{l} / \mathrm{m}]$ for the $1,200-\mathrm{cfm}\left[0.56 \mathrm{~m}^{3} / \mathrm{s}\right]$ prototype, while effectively suppressing droplet carryover).

\section{PERFORMANCE OF A LOW-FLOW LIQUID- DESICCANT REGENERATOR}

The low-flow technology that has been successfully applied to the liquid-desiccant conditioner will also improve the performance of the regenerator. In addition to eliminating desiccant carryover and reducing pressure drops, low-flow technology will increase the regenerator's COP beyond that of conventional packed-bed regenerators. Furthermore, these efficiency improvements extend to lower regeneration temperatures, making the low-flow liquid-desiccant air conditioner attractive in distributed generation applications with both engines and PEM fuel cells, as well as solar thermal collectors.

The 21-plate model of the low-flow regenerator that is shown in Figure 5 was operated under controlled conditions at NREL's Advanced Thermal Conversion Lab. Its performance was mapped over a range of desiccant concentrations, operating temperatures, air velocities, and water flow rates.

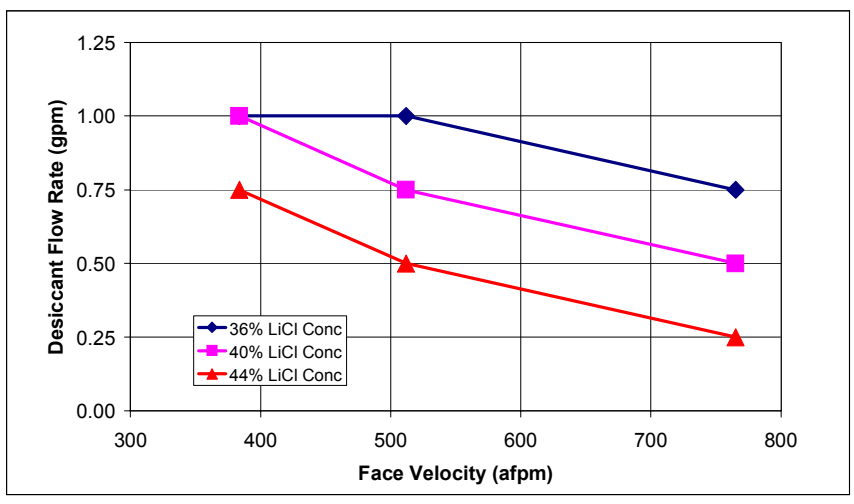

Figure 10 - Operating envelope for no carryover based on visual inspection 


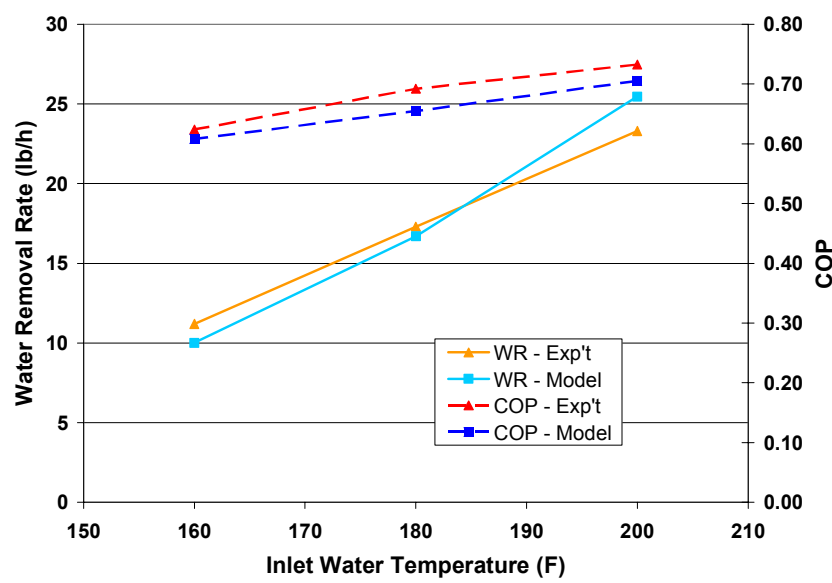

Figure 11 - Water removal and COP of a low-flow regenerator

Figure 11 shows the water removal (WR) and the COP of the low-flow regenerator when concentrating a solution of lithium chloride from $36 \%$ to $40 \%$. The air velocity at the face of the regenerator is $100 \mathrm{sfpm}(0.51 \mathrm{~m} / \mathrm{s})$, and inlet air conditions are $86 \mathrm{~F}, 0.01649 \mathrm{lb} / \mathrm{lb}$ and $12.1 \mathrm{psi}(30 \mathrm{C}, 16.5 \mathrm{~g} / \mathrm{kg}$, and $83.4 \mathrm{kPa}$ ). The test was conducted to simulate operation with an interchange heat exchanger that had an effectiveness between $65 \%$ and $80 \%$. Also shown on this figure are the predictions of AILR's computer model for the regenerator.

The measured COP for the regenerator ranged from 0.62 with $160 \mathrm{~F}$ (71.1C) hot water to 0.73 with $200 \mathrm{~F}$ (93.3C) hot water. Both the measured water removal rate, and the COP agreed well with the computer predictions.

The operation of the regenerator with an air-to-air heat exchanger (AAHX) that recovers thermal energy from the regenerator exhaust air to preheat the incoming scavenging air was simulated by increasing the inlet air temperature to the regenerator without changing its humidity. As shown in Figure 12 , these tests show that a $50 \%$ effective AAHX would increase the regenerators COP from 0.73 to 0.79 when operating with $200 \mathrm{~F}$ (93.3C) hot water and a 100 -sfpm (0.51$\mathrm{m} / \mathrm{s}$ ) face velocity. (The $30 \mathrm{lb} / \mathrm{hr}$ that is the full scale for the $\mathrm{x}$ axis in Figure 12 equals $13.6 \mathrm{~kg} / \mathrm{hr}$.) The data in this figure

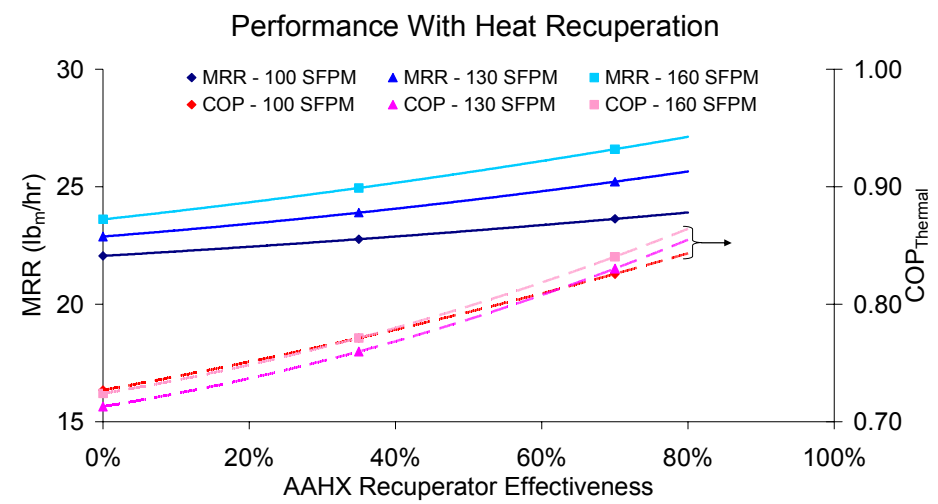

Figure 12 - Performance of the low-flow regenerator with heat recuperation also show the effect of face velocities of 100, 130, and 160 $\operatorname{sfpm}(0.51,0.66$, and $0.81 \mathrm{~m} / \mathrm{s})$ on both the rate of water removal (MRR, which is the same as the parameter WR that was used earlier) and COP.

\section{THE FIELD OPERATION OF A 6,000-CFM ROOFTOP LIQUID-DESICCANT AIR CONDITIONER}

Figure 13 shows a rooftop liquid-desiccant air conditioner that is designed to cool and dry $6,000-\mathrm{cfm}\left(2.83 \mathrm{~m}^{3} / \mathrm{s}\right)$ of ventilation air. The air conditioner includes a low-flow conditioner and regenerator. It also includes a 400,000-Btu/h $(117.2-\mathrm{kW})$ gasfired hot-water heater that meets the thermal requirements of the regenerator at $250 \mathrm{lb} / \mathrm{h}(113.6 \mathrm{~kg} / \mathrm{h})$ of water removal. In solar applications, this hot-water heater may be retained as a back-up to the solar collectors or it may be eliminated. A 25ton $(87.9-\mathrm{kW})$ cooling tower provides $75 \mathrm{gpm}(4.73 \mathrm{l} / \mathrm{s})$ of cooling water to the conditioner.

The field operation of the rooftop liquid-desiccant air conditioner began in late September 2005 and continued for 4 weeks at which time ambient conditions in New Jersey became too cold and dry to permit meaningful testing. During the test, the air conditioner operated completely under automatic control, including PID loops for ventilation airflow, boiler temperature, and desiccant concentration. The controller also sequenced all startup and shutdown procedures for the conditioner, regenerator, boiler and cooling tower.

The liquid-desiccant air conditioner operated throughout the test with a one-half scale regenerator. When the air conditioner first operated in the fall of 2004, it included a first-generation regenerator that eventually proved not sufficiently reliable for a commercial product. The hangingplate regenerator that was described in an earlier section was developed to replace the older design. However, because the new regenerator was not ready until the fall of 2005 , when cooling loads would be well below peak summer values, the process of retrofitting the air conditioner with the new regenerator was simplified by installing a unit with one-half the required water-removal capacity.

The highest latent cooling during the test, $141 \mathrm{lb} / \mathrm{h}$ $(64.1 \mathrm{~kg} / \mathrm{h})$ of water removal, occurred on October 5. Table 1 summarizes the air conditioner's performance for a 43-minute period on that day when ambient conditions averaged $77.7 \mathrm{~F}$ and $0.01229 \mathrm{lb} / \mathrm{lb}(25.4 \mathrm{C}$ and $12.29 \mathrm{~g} / \mathrm{kg})$.

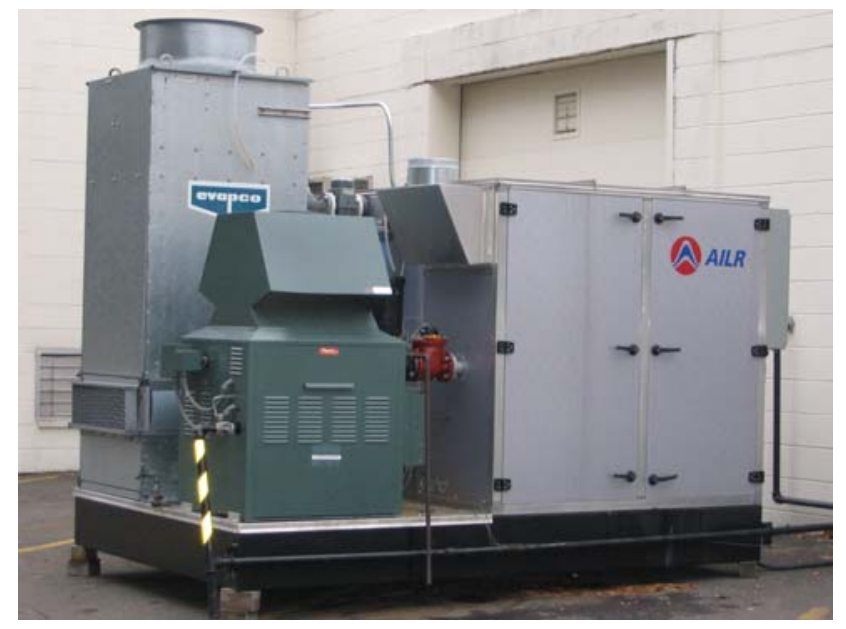

Figure 13 - Prototype of a 6,000-cfm rooftop liquiddesiccant air conditioner 
Table 1.

\begin{tabular}{|l|c|c|}
\hline Date & & 5 - October \\
\hline T Ambient & F & 77.7 \\
\hline W Ambient & Ib/lb-d.a. & 0.01229 \\
\hline T Supply & F & 78.9 \\
\hline W Supply & Ib/lb-d.a. & 0.00572 \\
\hline C Des Conditioner Inlet & $\mathrm{lb} / \mathrm{lb}$ & 0.403 \\
\hline C Des Conditioner Outlet & $\mathrm{lb} / \mathrm{lb}$ & 0.377 \\
\hline Conditioner Des Flow & $\mathrm{gpm}$ & 3.19 \\
\hline Conditioner Air Flow & $\mathrm{cfm}$ & 4772 \\
\hline Q Air Total & $\mathrm{Btu} / \mathrm{h}$ & 143,190 \\
\hline Q Air Latent & $\mathrm{Btu} / \mathrm{h}$ & 149,574 \\
\hline Q Coolant & $\mathrm{Btu} / \mathrm{h}$ & 170,347 \\
\hline Water Removal & $\mathrm{lb} / \mathrm{h}$ & 141.2 \\
\hline T Hot Water Regen Inlet & $\mathrm{F}$ & 210.1 \\
\hline Regenerator Des Flow & $\mathrm{gpm}$ & 3.15 \\
\hline Regenerator Thermal COP & & 0.699 \\
\hline Boiler Efficiency & & 0.688 \\
\hline IHX Effectiveness & & 0.557 \\
\hline
\end{tabular}

During this period, the latent and total cooling supplied by the conditioner were within $3 \%$ of the values predicted by the computer models that were used to design the unit.

Both the efficiency of the boiler and the effectiveness of the interchange heat exchanger (IHX) were lower than expected. A possible cause of the IHX's poor performance may have been that it was not completely purged of air. A new design for the IHX will be installed in the rooftop air conditioner before tests begin in 2006 , and better performance is expected.

The nominal efficiency of the boiler is $79 \%$ at full firing. During the period reported in Table 1, the boiler operated at about $50 \%$ of full firing. It is probable that at partload firing, the air-to-fuel ratio of the combustor is too lean, which is degrading efficiency.

The COP of the regenerator during the test period was 0.699. This good COP was achieved despite the poor performance of the IHX. Also, the regenerator did not use an air-to-air heat exchanger to preheat the scavenging air using the warm, humid exhaust from the regenerator.

At full load, the parasitic power requirements for the roof-top air conditioner are

$\begin{array}{lr}\text { cooling tower fan } & 1,600 \mathrm{~W} \\ \text { coolant pump } & 1,100 \mathrm{~W} \\ \text { strong desiccant pump } & 200 \mathrm{~W} \\ \text { weak desiccant pump } & 200 \mathrm{~W} \\ \text { hot-water pump } & 700 \mathrm{~W} \\ \text { process fan } & 2,200 \mathrm{~W}\end{array}$

(at 0.5 in. w.c. external pressure).

\section{CONCLUSION}

A new generation of liquid-desiccant cooling systems is now being commercialized that will greatly expand the market for solar cooling. The distinguishing characteristic of the new technology is a desiccant flooding rate that is a factor of 10 to 20 lower than the rates now used in conventional packed-bed systems.

Compared to the technology now in use, the low-flow liquid-desiccant air conditioner will:

- have much lower pressure drops

- be more compact

- produce a greater cooling effect (e.g., lower $\mathrm{cfm} / \mathrm{ton}$ )

- more deeply dry the process air, and

- have a higher COP.

Perhaps most importantly, both the low-flow conditioner and regenerator will operate without the entrainment of desiccant droplets by the air streams (i.e., zero desiccant carryover, which greatly reduces maintenance).

The advantages of low-flow liquid-desiccant technology have been demonstrated in laboratory and field operation. In a controlled laboratory test, a low-flow conditioner matched the dehumidification provided by a conventional packed-bed conditioner, but with less than onetenth the air-side pressure drop.

The low-flow technology used by the new liquiddesiccant conditioner was proven effective at suppressing droplet carryover, without the use of separate droplet filters or demisters, over a wide range of operating conditions. For operation with a $44 \%$ solution of lithium chloride, a face velocity of $400 \mathrm{afpm}(2.0 \mathrm{~m} / \mathrm{s})$, and a total air flow of $1,388 \mathrm{acfm}\left(0.656 \mathrm{~m}^{3} / \mathrm{s}\right)$ droplet carryover was suppressed for all desiccant flows less than about $0.75 \mathrm{gpm}(2.84 \mathrm{l} / \mathrm{min})$.

Tests of a scavenging-air regenerator that uses the low-flow technology showed that both water removal and COP were close to the predictions of the computer model that was used to design the regenerator. This regenerator could effectively run on heat provided by either glazed, flat-plate collectors, or evacuated-tube collectors. With an air-to-air heat exchanger that recovers thermal energy from the regenerator's exhaust air, the regenerator will have a COP of 0.79 when concentrating a solution of lithium chloride from $36 \%$ to $40 \%$ and supplied with hot fluid at 200F (93.3C).

Although not unique to the low-flow technology, the storage of concentrated liquid desiccant provides an effective means to match cooling loads with the availability of solar energy. The relatively low cost for desiccant storage, particularly systems that use calcium chloride, will ensure a high utilization of the thermal energy provided by the collectors, thereby improving the competitiveness the solar cooling system.

\section{ACKNOWLEDGEMENTS}

The authors wish to thank the U.S. Department of Energy's Distributed Energy Program, which is headed by Ms. Patricia Hoffman. The support of this program was critical to the successful development of this technology for use in natural gas fired and distributed generator waste heat applications. 


\section{REFERENCES}

Coellner, James, "Energymaster-Desiccant Cooling in the Marketplace," Proceedings of the Desiccant Cooling and Dehumidification Opportunities for Buildings Workshop, Chattanooga, TN; June 1986.

Jilier Science and Technology, Product Brochure, Zhejiang, China, 2005.

Kessling, Laevemann, and Peltzer, "Energy Storage for Solar Desiccant Cooling Systems," Solar Energy, Vol. 64, Nos. 46, pp 209-221, 1998.

L-DCS Technology Website, http://www.l-dcs.com/ applications/solar.html, 2006.

Löf, "House Heating and Cooling with Solar Energy," Solar Energy Research, University of Wisconsin Press, Madison, pp. 33-46, 1955.
Lowenstein, A., Slayzak, S., Kozubal, E., and Ryan, J., "A Low-Flow, Zero Carryover Liquid Desiccant Conditioner," International Sorption Heat Pump Conference Proceedings, Interlocken, CO, 2005.

Robison, H., "Operational Experience with a Liquid Desiccant Heating and Cooling System," $18^{\text {th }}$ IECEC, Orlando, FL, 1983.

Schlepp and Schultz, "High Performance Solar Desiccant Cooling System: Performance Evaluations and Research Recommendations," SERI/TR-252-2497, 1984.

Slayzak, S. and Ryan, J., NREL's Advanced Thermal Conversion Laboratory," NREL/BR-550-34928, 2004. 


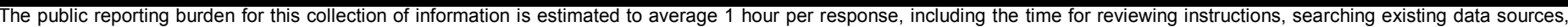

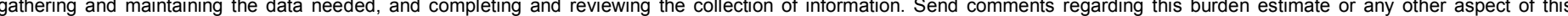

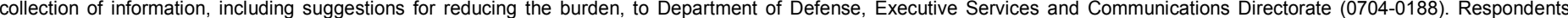

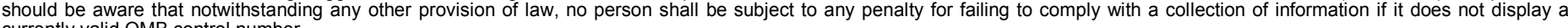
currently valid OMB control number.

PLEASE DO NOT RETURN YOUR FORM TO THE ABOVE ORGANIZATION.

\section{REPORT DATE (DD-MM-YYYY) July 2006 \\ 2. REPORT TYPE \\ Conference Paper}

4. TITLE AND SUBTITLE

A Zero Carryover Liquid-Desiccant Air Conditioner for Solar Applications: Preprint
3. DATES COVERED (From - To) 5a. CONTRACT NUMBER

DE-AC36-99-G010337

5c. PROGRAM ELEMENT NUMBER

6. AUTHOR(S)

A. Lowenstein, S. Slayzak, and E. Kozubal

5d. PROJECT NUMBER

NREL/CP-550-39798

5e. TASK NUMBER

DPT6.3001

5f. WORK UNIT NUMBER
7. PERFORMING ORGANIZATION NAME(S) AND ADDRESS(ES)

National Renewable Energy Laboratory

1617 Cole Blvd.

Golden, CO 80401-3393
8. PERFORMING ORGANIZATION REPORT NUMBER

NREL/CP-550-39798

9. SPONSORING/MONITORING AGENCY NAME(S) AND ADDRESS(ES)

10. SPONSOR/MONITOR'S ACRONYM(S) NREL

11. SPONSORING/MONITORING AGENCY REPORT NUMBER

\section{DISTRIBUTION AVAILABILITY STATEMENT}

National Technical Information Service

U.S. Department of Commerce

5285 Port Royal Road

Springfield, VA 22161

\section{SUPPLEMENTARY NOTES}

\section{ABSTRACT (Maximum 200 Words)}

A novel liquid-desiccant air conditioner that dries and cools building supply air will transform the use of direct-contact liquid-desiccant systems in HVAC applications, improving comfort, air quality, and providing energy-efficient humidity control.

\section{SUBJECT TERMS}

Dehumidifier; Liquid Desiccant; Air Conditioner; HVAC

\begin{tabular}{l}
\hline \multicolumn{3}{|l|}{ 16. SECURITY CLASSIFICATION OF: } \\
\hline \begin{tabular}{l|l|l|} 
a. REPORT & b. ABSTRACT & c. THIS PAGE \\
Unclassified & Unclassified & Unclassified \\
\hline
\end{tabular} \\
\hline
\end{tabular}

17. LIMITATION
OF ABSTRACT
UL

18. NUMBER OF PAGES

19a. NAME OF RESPONSIBLE PERSON

19b. TELEPONE NUMBER (Include area code) 